\title{
PHILOSOPHY
}

\section{TO THE PROBLEM OF FREEDOM IN THE CREATIVITY OF I. BERLIN}

\author{
G. Korotich ${ }^{1}$ \\ DOI: http://doi.org/10.15350/L_26/11/2
}

\section{Abstract}

The peculiarities of research by I. Berlin on the problem of freedom are analyzed. The essence of the concepts he proposed is "negative freedom" and "positive freedom" are disclosed. The connection between the problem of freedom and the problem of pluralism of values, human nature, contradictions in public life is shown.

Keywords: freedom, positive freedom, negative freedom, individual freedom, value, man, pluralism.

Исайя Берлин (1909 - 1997) - английский философ и историк, который родился в Латвии, во время революции 1917 года жил в Петрограде, затем эмигрировал в Англию, где прожил большую часть своей жизни. Основной темой размышлений И. Берлина была проблема свободы, к анализу которой он приглашал своих читателей или собеседников, избегая однозначных выводов и намечая новые аспекты последующих исследований. Среди научных трудов, посвященных анализу творчества И. Берлина, следует отметить статьи О.Л. Грановской, в которых автор знакомит со своим взглядом на политическую философию И. Берлина как на диалог западного и русского мировоззрений и культур, а также с аксиологическими взглядами мыслителя [2], [3]. А. Паньковский глубоко исследует особенности либерализма философа, главное внимание направляя на аксиологический аспект его творчества, понимание плюрализма как «метаценности», определяя концепцию И. Берлина как версию этического реализма [4]. В своей статье В. Н. Шаповал осуществил попытку сравнительного анализа социально-философских взглядов И. Берлина и Ф. Хайека относительно проблемы свободы в рамках общетеоретической концепции каждого из них [5]. По его мнению, деление И. Берлином свободы на «негативную» и «позитивную» является достаточно продуктивным, негативная свобода ассоциируется у философа с понятием независимости. Однако В. Н. Шаповал не соглашается с тем, как И. Берлин раскрывает содержание понятия «позитивная свобода», а также уточняет содержание понятия «негативная свобода»: когда речь идет о независимости, то следует иметь в виду не

${ }^{1}$ Galina Korotich, Candidate of Philosophical Sciences, Associate Professor, State Higher Education Establishment «Pryazovskyi State Technical University», Mariupol, Ukraine. 
только независимость от злой человеческой воли, но также от естественных, объективных сил. В. В. Оглезнев и С. Н. Брянский попытались осуществить критический анализ концепции свободы И. Берлина средствами аналитической философии языка [6]. Однако их статья по большей части посвящена взглядам не И. Берлина, а Дж. МакКалума. Интересно, что в отличие от В. Н. Шаповала, ученые не считают эффективным деление И. Берлином свободы на «негативную» и «позитивную». Статья М. О. Плющевой посвящена анализу философом концепции свободы сквозь призму гендерной проблемы [7]. В целом, анализ научной литературы, посвященной пониманию И. Берлином проблемы свободы, обнаруживает неоднозначную оценку взглядов философа со стороны ученых и позволяет сделать вывод, что эта тема далеко себя не исчерпала и нуждается в последующем изучении. Поэтому целью данной статьи является анализ особенностей исследования И. Берлином проблемы свободы. Это представляется важным и с точки зрения «вечной» актуальности исследования понятия «свобода», и с учетом современных социокультурных реалий.

И. Берлин заинтересовался философией в конце двадцатых - начале тридцатых годов XX века, во время учебы в оксфордской аспирантуре. Эта заинтересованность развилась в серьезное увлечение, привела ученого к преподаванию философии, к анализу актуальных тогда дискуссионных философских тем. Одна из них - это проблема природы смысла, интерес к которой был сформирован философами Венской школы. Еще одной философской проблемой, которой тогда занимался И. Берлин, был феноменализм, обсуждавший вопрос: основывается ли человеческий опыт лишь на ощущениях, или же существует реальность, независимая от чувственного опыта? Философ не разделял точку зрения рационалистов и объективных идеалистов, считая ошибочной работу тех, кто пытался обнаружить бесспорные ответы, которые засвидетельствовали бы, по его выражению, состояние «общей интеллектуальной уверенности». Когда И. Берлин по окончании Второй мировой войны вернулся к занятиям философией, его внимание оказалось приковано к двум философским проблемам, которые, по словам ученого, надолго определили его размышления [8, с. 3]. Первая из них получила у философа название «монизм»; к ней он относился весьма критически. Речь идет об осмыслении точки зрения, согласно которой на каждый вопрос должен существовать только один истинный ответ и только один правильный путь, который ведет к этому ответу. На самом деле человечество является многоликим в культурном плане, и универсально правильных ответов не существует. Можно усмотреть наличие в разных культурах сходных главных ценностей, правил поведения, но они проявляются в них своеобразно. Мыслитель замечает, что жизнь человека или культуры не навязывается кем-то «сверху», она создается теми, кто ее проживает, ее творит. Человек сам создает ценности, сам задает направление своей жизни и сам несет за это ответственность. Однако здесь, по мнению И. Берлина, возникает новая опасность. Когда мы говорим, что человек сам создает ценности, то кого именно мы имеем в виду под словом «человек»: индивида (в частности, индивида-аутсайдера) или народ, церковь, 
партию, определенную социальную группу? В случае такого «коллективного» понимания «Я» не исключен вариант, когда индивид перестает иметь самостоятельную ценность вне его принадлежности к партии или классу, к определенному движению или народу, то есть к некоторому «Сверх-Я», в котором он «растворяется». И. Берлин называет идею абсолютного подчинения индивида определенному «Сверх-Я» страшной, опасной, и такая оценка является справедливой. Эти размышления привели ученого к выводу о необходимости существования плюрализма идеалов и ценностей. Именно плюрализма, поскольку существует возможность взаимопонимания, взаимного уважения между разными системами ценностей. И. Берлин подчеркивает, что ценности - объективны, соответствуют человеческой природе, помогают сохранять человеческое подобие. Философ считает, что у всех людей должны быть общие ценности, иначе они перестанут быть людьми, и в то же время, их ценности должны отличаться, потому что иначе люди перестанут отличаться один от другого [8, с. 8]. При этом не исключен конфликт ценностей. Поскольку возможность взаимного уважения между системами ценностей все же существует, существует плюрализм ценностей, то существует также терпимость к чужой точке зрения и либеральные идеалы, которые невозможны ни при господстве монизма с его единственным набором «правильных» ценностей, ни при господстве релятивизма, который приводит к потере терпимости и уважения даже там, где они возможны. И. Берлин справедливо замечает, что из такого противопоставления может возникнуть экстремальный вариант национализма, абсолютизирующего значение определенной нации, ставящего ее над другими, считая последних лишь материалом и средством для осуществления целей высшей нации. Эти размышления и привели И. Берлина к углубленному исследованию проблемы свободы.

Рассуждая о свободе, И. Берлин пишет, прежде всего, о свободе действий, особенно политических. Как и многие исследующие тему свободы, ученый разграничивает два понятия - «негативную свободу» и «позитивную свободу». Обе свободы являются основными человеческими целями. И хотя содержание понятия «негативная свобода» определить достаточно трудно, определение все же существует. Под негативной свободой (или «свободой от (чего-то)») И. Берлин, в первую очередь, понимает отсутствие препятствий, которые мешают осуществлению определенного действия [8, с. 9]. Степень негативной свободы зависит от меры отсутствия созданных кем-то препятствий, от того, насколько человек свободен идти той или иной дорогой, от количества таких дорог, из которых он может выбирать свою. Препятствия создаются внешним миром с его институциями и деятельностью других людей, а также биологическими, психологическими законами. И. Берлин уточняет, что недостаточно понимать под негативной свободой свободу делать то, что хочешь, поскольку тогда, например, человек может освободиться от препятствий на пути исполнения собственных желаний, освободившись от последних. Смысл понятия «негативная свобода» содержится в ответе на вопрос об объеме пространства, в пределах которого человек или группа людей может делать, что хочет или 
быть такими, которыми они хотят быть. Чем больше пространство невмешательства, тем шире моя свобода. Однако эта сфера не является безграничной, так как люди взаимозависимы. На практике иногда бывает нужно ограничить свободу одних, чтобы иметь возможность обеспечить ее другим. А если так, то какая сфера человеческого существования должна оставаться независимой от социального контроля? И. Берлин отвечает на этот вопрос таким образом (и можно согласиться с его мыслью): необходимый минимум свободы - тот, отказ от которого посягает на сущность человеческой природы $[1$, с. 49]. Однако при этом возникает вопрос относительно определения сущности человека, справедливо замечает ученый.

Если негативная свобода определяется ответом на вопрос «насколько мной управляют?», то позитивная свобода определяется ответом на вопрос «Кто мной управляет?», «Чем или кем детерминирована моя деятельность?» и т. п. Позитивная свобода - это «свобода для (чего-то)». Понятие такой свободы становится понятнее после размышлений над вопросом: «Где находится источник давления или вмешательства, который кого-то вынуждает делать определенные вещи, быть именно таким, а не другим?».

Как считает И. Берлин, уточняя понятие негативной свободы, мы ее лишены, если достижению нашей цели так же целеустремленно мешают определенные обстоятельства, например, люди, которые сознательно действуют в этом направлении. Если же человек, имея, например, плохое здоровье, не может достичь цели, то это уже не является ситуацией отсутствия свободы. Несвобода появляется, когда я чувствую чужое вмешательство, влияющее на мой выбор действий. Например, если кто-то в условиях тоталитарного государства предает товарища под угрозой пыток, из страха потерять работу, то такой поступок свободным назвать нельзя. Конечно, сделан определенный выбор, но на него влияли внешние обстоятельства, потому наличия альтернатив поведения для утверждения свободы недостаточно. Как уточняет философ, объем моей свободы зависит от количества возможностей, которые открываются, от того, насколько легко реализовывать эти возможности, насколько они для меня являются важными, от того, способны ли преднамеренные человеческие действия раскрыть или блокировать их, от того, как ценит такие возможности общество, в котором я живу [1, с. 50]. Из этого можно сделать взвод, что И. Берлин признает необходимость существования в обществе системы общепринятых высших ценностей, среди которых - свобода, справедливость, закон, человеческое достоинство, мудрость, счастье, милосердие, безопасность и т. п.

Заметим, что И. Берлин не видит связи между личной свободой и демократической формой правления. Он констатирует лишь существование принципиальной разницы между такими вопросами (и ответами на них), как «Кто мной управляет?» и «Насколько вмешивается власть в мои дела?» (хотя идея самоуправления, как признает философ, может лучше гарантировать мои права). В сущности, речь опять идет об отличиях между понятиями негативной и позитивной свободы. 
Как справедливо уточняет ученый, «позитивное» содержание слова «свобода» возникает из желания быть хозяином самому себе, осуществлять собственные задачи и намеченную самостоятельно стратегию [1, c. 51]. «Самостоятельно» - значит «в соответствии со своим «Я», со своей подлинной природой. Однако бывает так, что человек не понимает своего «Я» и не ориентируется в системе ценностей, вообще не видит смысла над этим думать, или же его понимание не устраивает определенную сверхличностную сущность (класс, партию, государство, церковь, и т. п.). Тогда, и так уже случалось, эта сверхличностная инстанция берет на себя общественный труд растолковать это человеку, при этом отождествляя или подменяя его интересы своими интересами. И. Берлин подчеркивает, что в мире не было ни одного деспота-человека или коллективного диктатора (партии, например), которые бы не использовали такой метод аргументации с целью притеснения, объясняя, в чем заключается истинная свобода и истинное «Я» каждого человека, исходя из того, что на каждый вопрос есть только один правильный ответ, известный именно диктатору [8, с. 11]. Как очень точно замечает философ, триумф деспотизма наступает тогда, когда рабы говорят, что они свободны [1, с. 65]. Поэтому концепция позитивной свободы легче допускает обоснование манипуляции и насилие, потерю независимости, утрату личностного начала, чем концепция негативной свободы. Осмысливая это, И. Берлин опять обращается к связи понятия «свобода» и понятия «ценность». Свобода, как бы ее ни понимали, является вечным человеческим идеалом, ценностью. Если человек является высшей ценностью, целью, а не средством, то им невозможно манипулировать с помощью, например, социальных реформ. Если считать человека наивысшей ценностью, то должен ли кто-то вынуждать его подчиняться ценностям менее значимым? Может ли кто-то навязывать кому-то другому собственное видение счастья? Верным будет решение дать возможность выбирать ценности самому. Что должно быть основанием для такого выбора? Рассуждая над этой проблемой, И. Берлин замечает: в истории были случаи, когда люди, получающие в борьбе власть и свободу (реализуя негативное ее понимание), после достижения цели переходили на позиции свободы позитивной. В качестве примера И. Берлин пытается рассмотреть позитивную свободу, достигнутую с помощью разума, имея в виду (правда, несколько им искаженные) взгляды Гегеля, Маркса и других мыслителей, направляющих человека на сознательные действия по своему освобождению, на самоконтроль, на рациональное самовоспитание [1, c. 55-56]. Как предотвратить возникновение противоречий с другими «Я»? Где пролегает граница между моими рационально определенными правами и аналогичными правами других? И. Берлин подвергает критике взгляды тех рационалистов, которые подчеркивают, что в идеальном, разумном государстве должны доминировать справедливые законы, свободно принятые всеми разумными людьми в качестве единственно истинного пути решения любой проблемы. Если вселенной руководит разум, то исчезает потребность в насилии в любом его понимании. В разумном об- 
ществе все правильные решения реальных проблем являются совместимыми, составляют единое целое, образовывая гармоничный мир. Разумный человек знает природу вещей и людей, может их объяснить другим, может помочь им раскрыть свое подлинное «Я», стать лучшими, развить в них осознание необходимости свободного разумного саморазвития. Разум должен преодолеть сопротивление страстей и желаний, которые охватывают нас в жизни. Тогда будет создано идеальное общество, законы которого свободу не будут ограничивать, потому что они будут позволять человеку делать то, чего он, разумный и ответственный, и так не захочет делать. Мудрецы-правители знают лучше любого человека, что для него является оптимальным, какой должна быть его жизненная цель, иронизирует И. Берлин. Все конфликты возникают из-за столкновения разума с неразумными проявлениями, считают рационалисты. Поэтому для блага человека его можно побуждать действовать разумно, поборов иррациональные желания и импульсы, даже если это будет требовать от него жертв (например, отдать свою жизнь). Однако такие мыслители-рационалисты с уклоном в монизм сталкиваются с проблемой: как сделать людей разумными и свободными? Ответ «благодаря образованию», через разумное самонаправление может, с точки зрения ученого, привести к диктатуре, к тоталитаризму и отсутствию реальной свободы. Человек - не статистическая единица, он хочет чувствовать себя ответственным, самостоятельно действующим лицом, целостным со своей собственной волей, в соответствии с которой он действует и хочет, чтобы его таким считали другие. У людей есть собственные потребности и интересы, которыми могут жертвовать во имя определенной общей цели (отметим - часто очень абстрактной). Однако иногда это случается по их собственной воле. И. Берлин справедливо обращает внимание на то, что человек часто ищет как общественного признания, так и общения, понимания, общности интересов, братства и солидарности с определенной социальной группой, к которой принадлежит. Человек может желать свободы, признания, уважения со стороны общества и для этой социальной группы тоже. Это, по мнению И. Берлина, приводит к тому, что люди иногда отдают преимущество авторитарным демократиям в сравнении с самыми образованными олигархиями [1, с. 62]. Стремление к свободе смешивается со стремлением к социальному статусу. Возможно, что таким образом человек идет к свободе, как он ее понимает, если, например, считает, что руководить им должен кто-то «свой», с кем установлены братские отношения и солидарность, «идеальный» человек, которого добровольно признают «своим». Власть опирается на законы, запреты, указания, которые адресованы всем членам общества. Как при этом защитить негативную свободу? Как это согласовать с пониманием позитивной свободы как свободы самоопределения? Возникает необходимость в создании такого общества, где границы индивидуальной свободы (определенный минимум негативной свободы) не может перейти никто. Эти границы могут быть определены естественными правами, Богом, законами природы и т. п. И. Берлин метко замечает, что адепты негативной свободы желают ограничить власть как таковую, позитивной - взять ее в свои руки [1, 
c. 65]. В этом - кардинальная разница, то есть не только различные интерпретации одного и того же понятия, а непримиримые подходы к совершенно отличающимся жизненным целям. Это необходимо признать, даже если в реальной жизни часто нужно бывает искать компромисс, основанием чего есть осознание, что обе свободы являются проявлениями высших человеческих ценностей.

Совет ученого искать компромисс между обеими свободами не означает, что он рассматривает диалектическую связь этих свобод в таком смысле, например, что «свобода для» включает и «свободу от», а последняя является значимой не сама по себе, а как «свобода для». Рассуждения И. Берлина по поводу свободы лишены четких выводов, скорее, это предложение проанализировать многомерность этого понятия и плюрализм методов его исследования. Собственную позицию он противопоставляет попыткам упрощенно, однозначно, в отрыве от реальной жизни представить себе сущность свободы. Очень важно, что И. Берлин много внимания уделяет самоопределению индивида, его индивидуальной свободе, рассматривая ее в связи с понятиями негативной и позитивной свободы. Человек, исходя из собственного жизненного опыта и эмпирических наблюдений за общественной жизнью, которая постоянно изменяется, имеет основания сделать вывод о несовместимости базовых человеческих ценностей, о необходимости постоянно делать сложный выбор между ними. Цель не оправдывает средства, тем более что идет речь, по мнению философа, о нереальной цели построения идеального, совершенного общества. В то же время, И. Берлин замечает, что не осуждает идеал самосовершенствования (человека, нации, церкви, класса) как таковой; он подчеркивает, что именно понимание свободы как «позитивной» является средоточием требований национального и социального самоопределения, которые дают жизнь самым мощным и морально оправданным движениям нашего времени, и, не понимая этого, мы не поймем наиболее жизненно важные факты и идеи нашего века $[1$, с. 66]. Однако философ считает, что веру в возможность найти единственное решение, которое позволит гармонично соединить и осуществить разнообразные цели, можно доказательно опровергнуть, потому что будет всегда существовать возможность конфликта между целями и ценностями, между желаниями людей реализовать именно свой особенный, индивидуальный свободный выбор, который к тому же имеет конкретно-историческое измерение. Этот выбор зависит от наших моральных, религиозных, интеллектуальных, экономических, эстетических ценностей, связанных с нашими представлениями о человеке и его природе. Индивидуальная свобода не может быть безграничной, что не означает оправдания насилия, навязывания якобы правильного общего решения.

Как подытоживает И. Берлин, плюрализм со связанной с ним частью «негативной» свободы представляется более верным и гуманным идеалом, чем цели тех, кто видит в авторитарных структурах идеал «позитивного» самоопределения классов, народов и всего человечества. Он является более верным, поскольку признает множественность человеческих 
целей, несоизмеримость многих из них и их вечное соперничество. Плюрализм целей и ценностей не лишает людей во имя абстрактного идеала возможности реализовать в своей личной жизни то, что они считают необходимым. Очень важным для адекватного понимания точки зрения И. Берлина является его замечание, что в основе выбора людьми ценностей лежат фундаментальные этические категории и представления - часть человеческого бытия, их собственной идентичности [1, с. 67]. Ученый допускает, что с течением времени такие размышления о плюрализме и значении индивидуальной свободы могут потерять актуальность, потому что человеку присуща потребность выходить за свои индивидуальные границы, к чему-то общему и более высокому. Однако в настоящее время актуальным является именно плюрализм ценностей и целей в качестве основы индивидуальной свободы.

Подводя итог, заметим, что И. Берлину удалось показать ограниченность рационального восприятия понятия «свобода» и опасность абстрактных схем поиска однозначного и окончательного ответа в решении проблемы свободы. Рассуждения философа имеют большое методологическое и мировоззренческое значение, выявляют многомерность проблемы свободы, основой чего есть сложность, многомерность реальной жизни и попытки осознания этой сложности. И. Берлин раскрыл связь проблемы свободы с историческими реалиями, с противоречиями общественной жизни, с природой человека, проявляющейся разнообразным образом на индивидуальном уровне. Опираясь на принцип плюрализма (заметим, что граница между плюрализмом и релятивизмом у И. Берлина является все же очень тонкой), философ уделяет значительное внимание именно индивидуальному измерению понятия «свобода», пониманию индивида как ответственного творца своей судьбы, не являющегося средством для кого-то и чего-то. Можно утверждать, что деление на «позитивную» и «негативную» свободы (хотя и недиалектическое, так как эти понятия у ученого отделены друг от друга и очень редко пересекаются), помогает более глубоко понять сущность проблемы свободы, ее сложность (например, сложность самоопределения человека, который не только уникален, но и принадлежит к определенным социальным группам), ее аксиологический аспект.

\section{References}

[1] Берлин Исайя. Философия свободы. Европа [Электронный ресурс] / И. Берлин; предисловие А. Эткинда. - М. : Новое литературное обозрение, 2001. - 448 с. Режим доступа : http://library.khpg.org/files/docs/1329123681.pdf. - Дата последнего обращения: 06.11.2017.

[2] Грановская О. Л. Исайя Берлин: британский либерализм и русская философия (диалог мировоззрений) [Электронный ресурс] / О. Л. Грановская // Вопросы философии. - 2014. - № 9. - Режим доступа : http://vphil.ru/index.php?option=com content\&task=view\&id=1023\&Itemid=52. Дата последнего обращения: 03.11.2017. 
[3] Грановская О. Л. Ценностный плюрализм Исайи Берлина [Электронный ресурс] / О. Л. Грановская // Ценности и смыслы. - 2015. - Вып. 4 (38). - Режим доступа : https://cyberleninka.ru/article/n/tsennostnyy-plyuralizm-isayi-berlina. - Дата последнего обращения: 03.11.2017.

[4] Паньковский А. Агональный либерализм Исайи Берлина / А. Паньковский // Логос. - 2003. - № 4-5 (39). - С. 166-177.

[5] Шаповал В.Н. Понятие свободы в концепциях И. Берлина и Ф. Хайека [Електронний ресурс] / В. Н. Шаповал // Філософія : конспект лекцій : збірник праць. - Київ, 2012. - Режим доступа : http://www.info-library.com.ua/books-text11765.html. - Дата последнего обращения: 06.11.2017.

[6] Оглезнев В.В. Исайя Берлин и проблемы определения понятия «свобода» / В. В. Оглезнев, С. Н. Брянский // Вестник Томского государственного университета. Сер. Философия. Социология. Политология. - 2015. - Вып. № 4 (32). С. 318-325.

[7] Плющева М. О. Критика концепції свободи Ісайї Берліна [Електронний ресурс] / М. О. Плющева // Електронний каталог наукових робіт студентів та аспірантів : матеріали конференцій НТСА Філософського факультету КНУТШ. - Режим доступа : http://ntsaphil.univ.kiev.ua/web/pages/library.htm\#P. - Дата последнего обращения: 03.11.2017.

[8] Берлин Исайя. Мой интеллектуальный путь : пер. О. Л. Мартыненко [Электронный ресурс] : Интеллектуальные биографии / И. Берлин. - Режим доступа : http://www.ruthenia.ru/logos/number/2001 4/06.htm. - Дата последнего обращения: 03.11.2017. 